\title{
EL FUTURO Y LA INCERTIDUMBRE EN LOS ESTUDIOS HISTÓRICOS INMIGRATORIOS: \\ EL EJEMPLO DE NEUQUÉN, PROVINCIA PATAGÓNICA, 1930-1976
}

\author{
FUTURE AND UNCERTAINTY IN HISTORICAL \\ IMMIGRATION STUDIES: \\ THE EXAMPLE OF NEUQUÉN, PATAGONIAN PROVINCE, 1930-1976
}

\begin{abstract}
Mauricio Dimant ${ }^{*}$
\end{abstract}
Fechas de recepción y aceptación: 10 de junio de 2020 y 19 de octubre de 2020

DOI: 10.46583/scio_2020.19.725

Resumen: Este artículo busca introducir brevemente una discusión sobre el análisis de la concepción de futuro en los estudios históricos inmigratorios, a través de ejemplos en la región patagónica. Considerando que las conjeturas, imágenes y concepciones sobre el futuro -o sobre posibles escenarios en el futuro- se basan en datos e informaciones que afectan a la vida de los individuos y sus sociedades, este artículo identifica al menos dos formas de indagar sobre el rol de la imagen de futuro en los estudios históricos sobre la inmigración. El artículo discute sobre cómo la concepción respecto del futuro afectó al presente de los inmigrantes y la forma de relacionarse con su pasado, considerando que las imágenes de futuro formaron parte de la vida cotidiana de todos los pobladores. Tal perspectiva permite afinar los estudios históricos de la participación de los inmigrantes en los procesos socioeconómicos y

${ }^{a}$ Departamento de estudios españoles y latinoamericanos. Facultad de Humanidades. Universidad Hebrea de Jerusalén. Coordinador de la Unidad de América Latina en el Harry S. Truman Research Institute for the Advancement of Peace. Co-coordinador de la Asociación Internacional de Estudios Patagónicos.

${ }^{*}$ Correspondencia: Truman Institute, of 318 Mount Scopus. Hebrew University. 91095 Jerusalén. Israel.

E-mail: dimant@mail.huji.ac.il 
políticos, resaltando el papel de la incertidumbre en sus experiencias, prácticas e identificaciones, lográndose así profundizar la comprensión de la historia inmigratoria y su relación con la historia política, social y económica de las zonas de residencia y radicación.

Palabras claves: inmigración, imagen de futuro, incertidumbre, experiencias, decisiones, Patagonia.

Abstract: This article seeks to briefly introduce a discussion on the analysis of the conception of future in historical studies of immigration, through examples in the Patagonian region. Considering that the conjectures, images and conceptions about the future-or about possible scenarios in the future- are based on data and information that affect the lives of individuals and their societies, this article identifies at least two forms of inquire about the role of the conception of future in historical studies of immigration. The article discusses how the conception of the future affected the present of the immigrants and the way they related to their past, considering that the images of the future were part of the daily life of all inhabitants. Such a perspective makes it possible to refine historical studies of the participation of immigrants in socioeconomic and political processes, highlighting the role of uncertainty in their experiences, practices and identifications, and thus achieving a deeper understanding of immigration history and its relationship with the political, social and economic history of the settlement areas.

Keywords: immigration, image of future, uncertainty, experiences, decisions, Patagonia.

\section{$\S 1$ INTRODUCCIÓN}

El tiempo, o mejor dicho la concepción del tiempo, es un eje central en los estudios históricos sobre la inmigración. Estos estudios examinan principalmente prácticas y experiencias que tuvieron lugar en un momento que fue presente, y como implican un momento de cambio, algunas de ellas se analizan en relación con las prácticas de las zonas originarias de los inmigrantes. En otras palabras, los estudios históricos de la inmigración analizan un presente histórico considerando el pasado del inmigrante como base de referencia. 
Este artículo plantea la necesidad de incluir una perspectiva de análisis distinta, la cual incluya también las concepciones de futuro en aquel momento analizado: pensar la inmigración desde un marco analítico que considere no solo las experiencias previas del inmigrante, sino también su concepción de futuro dentro de aquel pasado examinado.

Los estudios históricos de las prácticas y experiencias de los inmigrantes en América Latina, por ejemplo, permiten observar cómo se fueron construyendo en distintos contextos imágenes colectivas sobre el futuro, y el papel que estas imágenes desempeñaron en la creación, rechazo y/o cambio de prácticas y actores sociales.

Entendiendo la inmigración también como un momento de negociación identitaria, los estudios históricos también permiten examinar cómo esta negociación encierra la imagen (o proyecto) de posibles escenarios en el futuro. Es en este contexto de negociación en donde, por ejemplo, discusiones políticas y modos de participación en la esfera pública, incluyendo la violencia, permiten relacionar aquellas experiencias particulares de la inmigración con aquellas experiencias no inmigratorias. Porque las concepciones sobre el futuro implican un amplio contexto de negociación.

En el marco de estas discusiones, y considerando la idea o imagen de futuro como uno de los ejes articuladores de experiencias, prácticas, decisiones e identificaciones en el proceso inmigratorio -como parte del proceso de lidiar con la incertidumbre- este artículo presenta brevemente algunas reflexiones para contribuir al estudio de la inmigración, partiendo de la historia regional ${ }^{1}$. Específicamente, en este artículo se propone discutir sobre la imagen de futuro y su rol en las experiencias laborales y políticas de inmigrantes identificados como miembros de minorías étnico-religiosas en la Patagonia, una zona periférica con una importante presencia de pueblos indígenas durante el proceso inmigratorio, la cual fue incluida al espacio nacional justamente por inmigrantes, muchos de ellos identificados como árabes y judíos.

${ }^{1}$ El "futuro" no ha recibido la suficiente atención académica en los estudios históricos. Este aspecto resulta central para el estudio de la inmigración, debido a la articulación entre las concepciones de tiempo y espacio que tienen lugar en el proceso inmigratorio. Sobre las experiencias individuales sobre el futuro, se recomienda tomar como referencias algunas discusiones dentro del ámbito de la psicología. Solo a modo de ejemplo, véase Seligman (2013). 
§2. EL ESTUDIO HISTÓRICO DE LA INMIGRACIÓN A PARTIR DE LAS CONCEPCIONES DE FUTURO: AlgunOS EJES DE DISCUSIÓN A PARTIR DE LOS ESTUDIOS DE AMÉRICA LATINA

Los análisis históricos de los procesos inmigratorios de minorías étnicoreligiosas presentan varios desafíos conceptuales que afectan muchas veces a sus propias agendas de investigación. Estos desafíos generalmente se traducen en perspectivas y discusiones en otras disciplinas que también analizan o piensan a la inmigración. A modo introductorio, se pueden mencionar dos cuestiones especialmente problemáticas: la integración y el espacio.

El carácter problemático del concepto de integración en los estudios históricos radica en varios presupuestos generalmente aceptados y no discutidos suficientemente, de los cuales tres presupuestos se encuentran presentes en gran parte de los análisis: (1) considerar a la integración como un estado, al cual el inmigrante debería alcanzar; (2) asumir la existencia de una oposición binaria frente a la integración, integrado-no integrado, o más-menos integrado, y (3) considerar a la integración de los grupos inmigratorios desde cierta imagen de homogeneidad de los actores.

Estos presupuestos han conducido a varios laberintos interpretativos, en donde se asume que un inmigrante tuvo el desafío de articular de alguna manera dos universos culturales: uno perteneciente a su origen, previo a la inmigración (traducido en prácticas y experiencias que serían propias de su zona de origen) y el otro de su presente, perteneciente a su nueva zona de residencia, el cual sería más o menos distinto o particular en sus prácticas y concepciones (Akmir, 2011; Gesser y Brauner, 2017; Noyjovich y Rein, 2017; Rein, 2015; Velcamp, 1997).

Las discusiones sobre la integración incluyeron ciertas preguntas sobre las condiciones en las cuales los individuos habrían decidido emigrar ( $p u s h$ factor) y aquellas condiciones que habrían atraído al inmigrante a dicha sociedad nueva para él (pull factor) (Rosas y Gay, 2015). Estas lecturas sobre la articulación de dos universos distintos condujeron a la búsqueda y utilización de nuevas categorías interpretativas, las cuales generalmente buscaron ampliar 
el marco de análisis de la integración, ya sea bajo la experiencia de diásporas, de prácticas transnacionales o como parte de una histórica oceánica. ${ }^{2}$

En el caso de la relación entre integración e identidad en la inmigración de minorías étnico-religiosas, algunos estudios históricos comenzaron a impulsar el estudio de esta relación como experiencias dinámicas unidas por un " $y$ " en lugar de un "o", buscando acentuar el estudio de las experiencias en los espacios de residencias, los cuales se asumieron como claves para comprender sus historias. Esto buscó disminuir de algún modo la perspectiva sobre la experiencia de origen como una característica pre-existente de carácter existencialista. Por ejemplo, en este marco de análisis se planteó la discusión entre considerar la identidad judía-argentina o argentina-judía, y cómo analizar sus diferencias y similitudes con otros argentinos no judíos y con otros judíos no argentinos (Lesser y Rein, 2008).

En el caso específico de los estudios históricos de la inmigración en América Latina, estas discusiones y perspectivas no lograron evitar un análisis limitado de la construcción social que varios grupos realizaron de su "madre patria", ocultándose muchas veces no solo el carácter "imaginario" o selectivo que tuvo muchas veces esta construcción, sino justamente su rol para negociar una pertenencia -aspecto que permite observar la ausencia de una tensión intrínseca entre ambos universos-. En otras palabras, el origen no consistió necesariamente en una identidad o experiencia preexistente.

Por ejemplo, en el caso de los inmigrantes árabe-parlantes de religión maronitas (la gran mayoría dentro de los inmigrantes árabes-parlantes en América Latina), el análisis de sus primeros pasos en el mercado laboral en Patagonia permite observar cómo estos utilizaron el manejo del idioma francés, y la imagen que construyeron sobre su pertenencia a la cultura francesa, como estrategia para construir un status social, en especial frente a ciertos actores locales, entre ellos los militares. Otro ejemplo es el de los inmigrantes judíos en la Patagonia y su relación con Israel, país que no consistió en el origen inmigratorio de ellos, pero que terminó convirtiéndose socialmente en una

\footnotetext{
${ }^{2}$ Existe una extensa literatura sobre estas temáticas, cada una con su propia dinámica. Resulta muy interesante, por ejemplo, re-lecturas de procesos a partir, por ejemplo, de las perspectivas con foco en procesos transnacionales.
}

SCIO. Revista de Filosofía, n. ${ }^{\circ}$ 19, Noviembre de 2020, 127-153, ISSN: 1887-9853 
especie de "madre patria" especialmente clave en su participación durante el proceso de provincialización impulsado en la zona al final del segundo Gobierno de Perón (1954).

El segundo concepto problemático que puede observarse en los estudios históricos de la inmigración es el de espacio, en particular por las preguntas asociadas a su conceptualización: ¿quién vivía en la zona antes de la llegada de los inmigrantes? Y por ello, ¿quién poseía más autoridad/legitimidad para tomar decisiones en él? En última instancia, ¿quién debería "adaptarse/integrarse" a qué?

Reconociéndose la tensión entre el derecho de libre determinación de los pueblos (y por ello el derecho de una comunidad de controlar sus fronteras) y los derechos individuales de movilidad, la concepción del espacio en los estudios históricos inmigratorios resultó problemática muchas veces por la falta de lecturas sobre las complejas construcciones, interpretaciones y usos del espacio dentro de los distintos países.

Por ejemplo, a pesar del claro y significante carácter federal de gran parte de los países de América Latina -o al menos de los principales países latinoamericanos analizados en los estudios inmigratorios (como México, Brasil y Argentina)-, el papel que tuvieron en el proceso inmigratorio las identidades colectivas asociadas a espacios subnacionales (provincias-regiones) no ha recibido la suficiente atención en estos estudios. Esto condujo a una jerarquización dentro de los estudios inmigratorios, en especial al estudiarse a las minorías étnico-religiosas: las investigaciones de sus experiencias en las ciudades capitales fueron asumidas como parte de una experiencia nacional, mientras que los estudios sobre sus experiencias en ciudades alejadas geográficamente de las capitales fueron consideradas como parte de una historia local.

Indirectamente, esta lectura diferenciada de las experiencias implicó que ciertos procesos centrales en la historia del país no hayan sido relacionados a los procesos inmigratorios, como las diferencias y los conflictos económicos entre regiones, provincias y ciudades por la distribución de recursos. Si bien los contextos políticos son considerados generalmente como claves para analizar la historia inmigratoria, en especial de las minorías étnico-religiosas, el papel de los conflictos o discusiones por recursos en la conformación de identidades colectivas provinciales-regionales no ha recibido la suficiente aten- 
ción. Como si las posibilidades materiales y las discusiones políticas en las diferentes localidades o poblados sobre las diferencias materiales no hubiesen afectado a las experiencias e identidades inmigratorias.

En el caso de la Patagonia, por ejemplo, este conflicto por recursos entre los poblados y el Estado nacional promovió la conformación de una identidad colectiva local que no necesariamente respondió a los criterios y prácticas comúnmente considerados como típicos de la identidad nacional. Más aún, muchas veces se opusieron a ellos.

Por ejemplo, los estudios sobre la historia política, social y cultural de la Patagonia resaltan la compleja y particular relación que tuvo lugar entre la población inmigrante, la población indígena y la población nacida bajo soberanía del nuevo estado nacional, una relación muchas veces reforzada por los conflictos por recursos entre los pobladores locales y las autoridades del Estado nacional.

Solo a modo de ilustración puede mencionarse el complejo proceso de autonomía provincial logrado por distintas zonas en la Patagonia, en donde inmigrantes (algunos identificados como miembros de minorías étnicoreligiosas), junto a indígenas e inmigrantes internos de otras provincias desempeñaron un papel protagónico en la consolidación de los nuevos Estados provinciales, justamente gracias al conflicto por recursos, consolidándose una identidad colectiva particular, en donde se articuló de un modo propio la membrecía a un nosotros provincial-nacional.

En Neuquén (provincia del norte de la Patagonia), el primer Gobierno provincial elegido democráticamente estuvo conformado por Ángel Edelman (de origen judío, hijo de pioneros de la provincia de Santa Fe) y su vice fue Alfredo Asmar (de origen árabe, hijo de inmigrantes libaneses dedicados al comercio en Buenos Aires). Y esto no fue un caso aislado: en todas las elecciones para el cargo de gobernador de la provincia de Neuquén durante los primeros 20 años de su vida provincial (hasta la dictadura de 1976), fueron elegidos únicamente miembros de minorías étnico-religiosas de origen inmigratorio (Mases, 2003; Iurono, 2005).

Más aún, los convencionales elegidos para redactar la primera constitución provincial de Neuquén fueron en su gran mayoría inmigrantes (no nacidos en el territorio provincial) con una visible participación de miembros de 
minorías étnico-religiosas de origen inmigratorio (Arias Bucciarelli, 2007). Esta participación se vio traducida en distintas discusiones públicas, como la que tuvo lugar a comienzos de octubre de 1957 para decidir si se debía o no incluir la frase "invocando la protección de Dios fuente de toda razón y justicia”, presente en la Constitución Nacional (Arias Bucciarelli, 2007; Pérez, Dardo y Seghesso, 2007; Ruffini y Blacha, 2013).

A partir de estas experiencias, este artículo propone contextualizar la concepción sobre el futuro en aquel presente histórico como una forma de ampliar el marco interpretativo de aquellas discusiones. Es decir, examinar las prácticas de los inmigrantes no solo a partir de su pasado y experiencia previa, sino también a partir del futuro imaginado en aquel contexto -futuro traducido en discusiones, prácticas y decisiones-. De esta manera este artículo busca contribuir al estudio de la inmigración en todas sus formas, ampliando el abanico de posibilidades para analizar distintos procesos, experiencias e identidades.

\section{§3. LA CONTEXTUALIZACIÓN HISTÓRICA DEL FUTURO EN EL ESTUDiO DE LA INSERCiÓN LABORAL DE LOS INMIGRANTES EN PATAgONIA. El CASO DE los ÁRABES EN NEUQUÉN}

La historia de la familia Sapag en Neuquén, en el norte de la Patagonia, despertó interés en investigaciones históricas porque esta familia de inmigrantes libaneses-maronitas, a través de los hermanos Elías, Felipe y Amado, participaron en la fundación y dirección del partido político provincial Movimiento Popular Neuquino (MPN), el cual nunca ha perdido una elección para el cargo de gobernador desde su fundación en 1962 hasta la actualidad (Bandieri, 2000; Iuorno, 2003; Favaro, 2004; Danza, 2013; Taranda, 2012). Lográndole ganar aún al partido político oficial de la fórmula Perón-Perón en 1973.

Elías, el hermano mayor, nació en el Líbano y emigró a Argentina en 1913 con sus padres Canaan y Nacira. Eligieron radicarse en el norte de la Patagonia ya que algunos familiares se encontraban viviendo o habían vivido en la zona desde 1902 (Sapag, 2008: 58).

La familia Sapag, al igual que otros inmigrantes, decidieron asentarse en la periferia de la actual provincia de Neuquén, primero en el poblado de Co- 
vunco y luego en los asentamientos de Zapala y Cutral Có, donde la familia Sapag desarrolló actividades comerciales a través de negocios de ramos generales. Luego diversificaron su actividad comercial al negocio de frutas y actividades mineras, paralelamente a la participación en actividades comunitarias locales (Iuorno, 2003).

Según el Censo Nacional de 1914, el número de inmigrantes provenientes de Medio Oriente en la Patagonia era el siguiente: Río Negro, 382 inmigrantes (206 en áreas urbanas, 176 en áreas rurales); Neuquén, 107 inmigrantes (71 en áreas urbanas, 36 en áreas rurales); Chubut, 203 inmigrantes (117 en áreas urbanas y 86 en áreas rurales); Santa Cruz, 78 inmigrantes (41 en áreas urbanas, 37 en áreas rurales); Tierra del Fuego, 5 inmigrantes (4 en zona urbana, 1 en zona rural) (Akmir, 1997: 71).

Independientemente de las importantes diferencias internas en cada una de las zonas en la Patagonia y según diferentes estimaciones demográficas, la región de Neuquén, esta área de 94.078 kilómetros, fue habitada entre 1895 y 1930 por unos 300 inmigrantes provenientes de Medio Oriente identificados con diferentes grupos étnicos y religiosos, quienes convivieron con unos 9.000 indígenas identificados con grupos Mapuches, Tehuelches y Ranqueles. La población total de esta zona fue de aproximadamente unos 30.000 habitantes, de los cuales un $45 \%$ de ellos procedía principalmente de Chile (algunos de origen indígena), España e Italia ${ }^{3}$.

Los inmigrantes provenientes de Medio Oriente arribaron a la Patagonia gracias al asesoramiento de conocidos o connacionales con mayor antigüedad en el país (quienes luego se convertirán en interlocutores de "la comunidad árabe" frente al Gobierno nacional), y generalmente a través de acuerdos comerciales con vendedores que poseían negocios ya instalados y que podían desempeñarse como mayoristas, quienes les entregaban mercadería en consignación con el compromiso de pagarla una vez vendida y con la obligación de continuar comprando mercadería del mismo proveedor.

\footnotetext{
${ }^{3}$ Estimación realizada a partir de los datos censales [República Argentina, Archivo General de la Nación, (AGN)], informes de Gobernadores de los Territorios Nacionales [Ibero-Amerikanische Institut (IAI)] y fuentes secundarias. Especialmente: F. Bandieri, O. Favaro y M. Morinelli (1992). Historia de Neuquén. Buenos Aires: Editorial Plus Ultra.
} 
Esta modalidad de inserción laboral (que no exigía una inversión previa ni conocimientos especiales, ni siquiera del idioma español) terminaría provocando que estos vendedores necesitaran expandirse a zonas alejadas y periféricas (o con poca competencia) para mantener un nivel de rentabilidad aceptable. Así, por ejemplo, estos vendedores originarios de Medio Oriente negociaron con líderes indígenas acuerdos comerciales, como el que Sapag recuerda de su pariente Simón Roca Jalil y el famoso líder indígena Manuel Namuncurá.

En Norpatagonia (en las actuales provincias de Neuquén y Río Negro), las principales firmas que comercializaban con inmigrantes de Medio Oriente eran Eldahuk Hnos., Medí y David y Miguel Yunes -aunque también existían otras firmas de inmigrantes españoles, italianos, judíos y criollos que utilizaban dicha modalidad de comercialización-.

En el caso de la familia Sapag, se relacionaron en un principio con la firma Linares, y por un tiempo (hasta 1932) mantuvieron en paralelo un negocio de ramos generales y realizaron la venta ambulante por distintos poblados del interior neuquino.

El análisis de la elección laboral realizada por estos inmigrantes, quienes eligieron el comercio como actividad económica en la Patagonia, permite observar cómo estas decisiones fueron motivadas por ciertas concepciones sobre el futuro, y no por experiencias previas o por su origen inmigratorio. En primer lugar, porque estos inmigrantes no habían realizado actividades comerciales antes de emigrar a América Latina.

En el caso de la familia Sapag, las principales actividades laborales en su zona de origen en Medio Oriente estuvieron relacionadas con la construcción y la agricultura, no con el comercio. Más aún, el tipo de participación en el comercio patagónico no consistió en una característica particular de los inmigrantes árabe-parlantes, sino que inmigrantes de distintos orígenes participaron de un modo similar, con una amplia colaboración entre ellos.

Pero no solo en la elección del rubro, sino también en el modelo de negocios o en la forma de trabajar o desarrollar esta actividad, los inmigrantes árabe-parlantes no lo hicieron de una manera distinta del resto de la población local, tanto inmigrante como autóctona. Por ejemplo, la estructura familiar y la división de tareas dentro de la familia no consistió en una "forma árabe" de 
hacer negocios, sino que otros inmigrantes de distintos orígenes desarrollaron en la zona una actividad comercial con estructuras similares. Más aún, no todos los inmigrantes provenientes de Medio Oriente participaron en el mercado laboral a través del comercio ni lo hicieron bajo una única modalidad.

Las posibilidades ofrecidas por el comercio a los inmigrantes en Patagonia pueden ser contextualizadas en distintos procesos en el país. En primer lugar, hasta los años cincuenta aproximadamente existían cuatro núcleos principales de rentabilidad comercial en la zona (tanto para "bolicheros" como para "mercachifles"): las estaciones ferroviarias, las zonas petroleras, las bases militares y las zonas indígenas o de crianceros.

De esta manera se puede comprender la ubicación geográfica seleccionada por aquellos inmigrantes dedicados al comercio, quienes eligieron radicarse en el territorio patagónico (como en el caso de la familia Sapag): cerca de bases militares (como en Covunco), cerca de pozos petroleros (como en Cutral Co-Plaza Huincul), cerca del ferrocarril (como en Zapala) y, en menor medi$\mathrm{da}$, entre poblados aislados del interior.

La familia Sapag junto con otras familias comenzaron su actividad económica en Neuquén a través de la comercialización de productos en el interior del territorio, todo ello gracias a la inversión estatal en infraestructura (especialmente a través de la construcción del ferrocarril, de las empresas estatales como YPF y de la instalación de bases militares), dado que estas medidas estatales fueron generando una especie de mercado interno que necesitaba de proveedores de distintos productos.

La familia Sapag, junto a otras familias de inmigrantes (no solo provenientes de Medio Oriente), encontraron en esta inversión estatal una oportunidad dado que este contexto promovió la colocación de productos de uso cotidiano en el interior del país. Pese a ello, los pobladores en la Patagonia poseían problemas de comunicación no solo con el centro económico y gubernamental del país (la ciudad y puerto de Buenos Aires), sino también entre sus diferentes zonas y poblados que la componían en aquellos años. Por ello, por ejemplo, hasta los años treinta era más fácil para los agricultores patagónicos exportar sus productos a través de Chile que desde la Argentina.

Solo a modo ilustrativo se puede mencionar que a pesar del litigio territorial entre Argentina y Chile, para los habitantes de Neuquén resultaba más 
cómodo recurrir al Estado chileno para solucionar distintas necesidades o problemas, un aspecto que generó que, hasta 1930 aproximadamente, en distintas zonas de Patagonia se comercializara con moneda chilena.

En este contexto, el comercio en Patagonia entre las diferentes ciudades y poblados significaba atravesar caminos peligrosos, ríos sin puentes, y por ello la necesidad de permanecer varios días en el descampado para llegar de una localidad a otra, y a nuevos pueblos por error o a pueblos abandonados, entre otros.

Esto generó la existencia de un marco de necesidades e intereses compartidos entre todos los habitantes de la zona, no solo entre los comerciantes, lo cual posibilitó una especie de contexto de cooperación entre distintos actores locales, quienes necesitaban del desarrollo local. Es en este contexto donde los inmigrantes dedicados al comercio no solo desarrollaron la venta ambulante en las zonas periféricas de la Patagonia, sino que incluyeron una metodología nueva y desconocida hasta ese momento: la venta en cuotas.

La introducción del sistema de venta en cuotas permite apreciar ciertas concepciones entre estos inmigrantes dedicados al comercio en dicho presente. En primer lugar, porque las dificultades locales no desestimularon sus inversiones en la zona, lo cual permite observar el carácter de temporario que adquirían los problemas en aquel presente. $\mathrm{O}$ en otras palabras, los cuales se asumían que necesariamente tenderían a mejorar. Esta visión positiva de las dificultades locales tenía una base clara: el activo rol del Estado en la zona.

La forma de comercializar motivó no solo un contacto constante de los comerciantes con sus vecinos y pobladores patagónicos, sino también el apoyo para el arribo y radicación de nuevos pobladores. Por lo tanto, como en el caso de la familia Sapag, estos inmigrantes se vieron motivados a participar en distintas organizaciones sociales y comunitarias de carácter local-vecinal (cooperadores, comisiones de fomento, clubes locales). En especial, porque esta inserción económica implicó la construcción de un marco de intereses comunes con la población local, aspecto que permitió en un primer momento una participación social en el ámbito local a través de distintas organizaciones de carácter vecinal, y luego a nivel político local. Entre otros, debido a la existencia de una preocupación común para que el poblado local continúe creciendo y desarrollándose. 
Los estímulos en Patagonia por parte del Estado nacional permiten contextualizar ciertas percepciones sobre el futuro en la sociedad local. En primer lugar, la forma de comercializar de los inmigrantes en la Patagonia visibiliza cierta percepción de seguridad, o al menos de falta de riesgo con respecto a la situación de la sociedad local, en especial en el futuro cercano. Un aspecto que habría contribuido a generar cierta previsión de ganancia y por ello de oportunidad de inversión.

El futuro en este contexto patagónico se traducía en crecimiento, en más posibilidades, en mejoras y ganancias a corto plazo, del cual los inmigrantescomerciantes podían verse y autopercibirse como protagonistas. Por ello el comercio se presentaba como un área de especial interés de inversión en esta concepción de futuro positivo a corto-plazo.

La inversión en la Patagonia a cargo del Estado Nacional en infraestructura -particularmente en la construcción del ferrocarril, pozos petroleros e instalación de bases militares- contribuyó a generar una concepción de seguridad sobre el futuro cercano en la sociedad local. Por ello, los inmigrantes dedicados al comercio se vieron motivados a participar en actividades que los colocaban como protagonistas de este crecimiento y en la consolidación de la sociedad local.

Solo a modo de ejemplo se puede mencionar la construcción del Ferrocarril del Sud, que cruzó el río Neuquén en 1902 y llegó a la ciudad de Zapala en 1913. Unos años más tarde, en 1918, el Estado argentino comenzó los trabajos de perforación petrolera en lo que terminaría transformándose en el poblado de Plaza Huincul, creado por el Estado para asegurar la residencia de los empleados en aquel pozo petrolero (Kloster, 1993). Estas obras se veían reforzadas por otras decisiones que contribuían tanto al asentamiento de nuevos pobladores como a la sensación de seguridad en la zona, como la decisión del año 1934 de construir el cuartel en Covunco del Regimiento de Infantería de Montaña 10 (Carrizo, 2009).

Por ello, a medida que las acciones del Gobierno federal buscaban incluir a la Patagonia en la economía nacional, se motivaba a la población local a participar en discusiones públicas (Favaro, 2005). En este contexto, la idea o imagen mistificada del pionero que habría arribado a la Patagonia para "mejorar la vida en la zona" se iba convirtiendo en parte de un discurso (o relato) 
local, el cual permitía que los nuevos habitantes de la zona se autopercibieran como "agentes de modernización" que aportaban al desarrollo de esa área (en función tanto de las políticas del Estado como también de las necesidades de los propios pueblos indígenas, por ejemplo).

En síntesis, la política del Gobierno nacional en la Patagonia generó un contexto que contribuiría a que la sociedad local conciba de un modo positivo y seguro su futuro a corto plazo en la zona. Esta conjetura promovió a los inmigrantes a una inserción laboral a través del comercio por las perspectivas de ganancias en el corto plazo, en paralelo a una sensación de seguridad sobre crecimiento constante de la población en la zona. Este tipo de concepción de futuro se verá reflejado en las actividades sociales y políticas a nivel local de estos inmigrantes dedicados al comercio, complementarias a su inserción laboral.

\section{§4. LA CONCEPCIÓN DEL FUTURO Y LA PARTICIPACIÓN POLÍTICA DE LOS INMIGRANTES: LOS CAMBIOS EN NEUQUÉN DURANTE LA DICTADURA ANTIPERONISTA (1955-1958)}

El golpe de Estado que derrocó al Gobierno de Juan Domingo Perón en 1955 llevó a cabo casi de inmediato varias políticas represivas contra los seguidores del "régimen depuesto". La dictadura autodenominada como "Revolución Libertadora" asumió sus funciones el 16 de septiembre de 1955, y apenas veinte días después, el 7 de octubre de 1955, puso en funcionamiento a la Comisión Nacional de Investigaciones mediante el Decreto Ley 479, con la intención de "desperonizar" a la Argentina (Spinelli, 2005; Tcach, 2003).

Para implementar la política represiva de "desperonización" en el país, el gobierno federal de la dictadura otorgó amplios poderes a la Comisión Nacional de Investigaciones, incluido el acceso a toda la información pública y privada sobre las actividades de los seguidores del peronismo. Los agentes de esta comisión estaban autorizados a investigar y arrestar a sospechosos, registrar domicilios particulares e instituciones públicas, secuestrar documentos privados, dictar medidas cautelares, acceder a los antecedentes privados de personas en empresas, organizaciones, etc. Todo esto se hizo con el fin de 
asegurar la investigación de todos aquellos individuos identificados con el peronismo, en especial dentro del Estado.

Para llevar a cabo esta política en todo el país, el Gobierno federal dividió las operaciones de la Comisión Nacional de Investigaciones, que estaba bajo la autoridad del Ministerio del Interior, entre regiones geográficas en una estructura piramidal, vertical y centralizada basada en la división del país en provincias.

Por ello, a tan solo doce días de ser creada a nivel nacional, la Comisión de Investigaciones se puso en funcionamiento en Neuquén (zona norte de la Patagonia) gracias al Decreto n. ${ }^{\circ} 128$, de 24 de octubre de 1955, la cual se encargó no solo de reemplazar a los funcionarios identificados con el peronismo en la región (por ejemplo, mediante la designación de nuevas autoridades municipales en las distintas localidades de Neuquén), sino también de informar e investigar todas aquellas actividades relacionadas con los seguidores del peronismo en este territorio, especialmente en el sector público y en las empresas estatales, para las cuales la Comisión Neuquina de Investigaciones creó subdivisiones administrativas con el fin de asegurar su efectividad ${ }^{4}$.

La Comisión Neuquina de Investigaciones publicó el 21 de noviembre de 1955 el Decreto Complementario n. ${ }^{\circ} 210$-un mes y medio después de su creación a nivel nacional-, y designó así la Comisión Estatal de Investigaciones de la Municipalidad de Neuquén, y el Decreto Complementario n. ${ }^{\circ} 271$, que estableció la Comisión de Investigaciones de la ciudad de Zapala el 30 de noviembre de 1955, los dos principales núcleos urbanos de Neuquén en aquellos años (Ruffini, 2016).

Esta división territorial de la Comisión Nacional de Investigaciones en Neuquén, que se duplicó en todas las provincias del país, tenía como objetivo lograr la "desperonización" en los rincones más recónditos del territorio. Por ejemplo, en el expediente 292 ("Reservado") de 9 de febrero de 1956, el presidente de la Comisión de Investigaciones del Municipio de Neuquén, capitán (D) Isidoro Herrera, informó al ministro de Gobierno de Neuquén, teniente

${ }^{4}$ Archivo General de la Nación, Argentina, (AGN), Ministerio del Interior, Provincias, Carpetas "La Comisión Nacional de Investigaciones". Folios 1956-1958. Sobre la represión en el norte de la Patagonia en este periodo se recomienda: Ruffini y Blacha (2013); Ruffini (2016). 
coronel Francisco S. Torres, del encarcelamiento de varios funcionarios identificados con el "régimen depuesto".

Si bien a lo largo de la dictadura autodenominada como "Revolución Liberadora" (1955-1958) las políticas de "desperonización" fueron un denominador común en toda la Argentina (tanto a nivel nacional como provincial/ municipal), esto no significó la ausencia de procesos locales específicos, diferentes y en algunos casos opuestos a los que tenían lugar a nivel nacional.

Por ejemplo, al mismo tiempo que la Comisión de Investigaciones sustituyó a las autoridades que habían sido designadas por el "régimen depuesto" en la ciudad capital de Neuquén (aspecto de las políticas represivas que se acentuaron tras la ascensión a la presidencia del general Pedro E. Aramburu el 13 de noviembre de 1955), los agentes de la Comisión de Investigaciones en Neuquén informaron a sus superiores en el Gobierno federal en Buenos Aires que varias de las políticas decididas por el Ejecutivo nacional no podrían ser aplicadas en las localidades de la Patagonia, situación que puede considerarse característica de otras localidades durante este período también.

Por ejemplo, el 31 de enero de 1956, diez días antes de presentar el informe de que las autoridades municipales de Neuquén habían sido encarceladas por sus responsabilidades durante el "régimen depuesto", el Ministerio del Interior recibió un informe de inteligencia ("Exp. 274, Reservado") indicando que a pesar del derrocamiento del gobierno de Juan Domingo Perón, resultaba imposible remover a todos los nombramientos peronistas en ciertas ciudades del territorio de Neuquén porque estos a menudo eran "las únicas personas en el lugar en condiciones de hacerse cargo, por razones de instrucción, ya que el resto de los habitantes son extranjeros con poco conocimiento del español, o argentinos analfabetos, o con muy poca educación"6.

Por otra parte, el 17 de enero de 1956, apenas unos veinte días antes de encarcelar a las autoridades del municipio de Neuquén designadas por el Gobierno de Perón, el comisario de la Policía de Neuquén, Eriserto B. Mena,

${ }^{5}$ Ministerio del Interior, Provincias, Carpeta "La Comisión Nacional de Investigaciones". Folio 181, box 3, 292r.

${ }^{6}$ (AGN), Ministerio del Interior, Provincias, Carpeta "La Comisión Nacional de Investigaciones". Año 1956, folio 1. 
envió una nota al ministro del Interior en Buenos Aires, informando de que la policía de Neuquén (también encargada de brindar apoyo logístico a la Comisión de Investigaciones) no podía aplicar plenamente las políticas antiperonistas de la dictadura militar dentro de su propia institución. Específicamente, Mena informó al ministro del Interior que no podía obedecer la orden de remoción de todos los policías de "origen peronista" en Neuquén (a pesar de su afiliación al "ex partido gobernante") "porque estos funcionarios están a cargo de comisarías muy pequeñas, con poca población y sin ninguna influencia en el orden político".

Sin desconocer la persecución y la represión contra los militantes y simpatizantes peronistas en Neuquén (en apego a las políticas de las autoridades locales impuestas por el Gobierno federal), las dificultades de aplicar a nivel subnacional las políticas represivas sancionadas por el Gobierno de la "Revolución Liberadora" se debió no solo a las características sociodemográficas de las provincias.

Los agentes del Ministerio del Interior que trabajan en Neuquén consideraron que varias de las decisiones tomadas por el Gobierno federal contra los simpatizantes de Perón resultaban contraproducentes en el contexto local de la Patagonia. Por ejemplo, según el informe de inteligencia número 149 del 10 de octubre de 1956, titulado "La realidad laboral de Plaza Huincul" (importante ciudad petrolera de la provincia de Neuquén), el Gobierno federal necesitaba entender que "el sindicalismo argentino tiene raíces nacionales y honestas. Especialmente cuando se trata de líderes del interior, como en este caso". En su informe, los funcionarios de inteligencia se quejaban de que "el sindicalista argentino que tuvo la mancha de haber acompañado al peronismo es el golpeado", mientras que los trabajadores afiliados al partido comunista continuaban en sus cargos o eran reincorporados a pesar de que "socavan la base de la identidad nacional argentina"7.

En este informe, los agentes a cargo de la represión en Neuquén, designados por el Gobierno de la "Revolución Liberadora", recomendaban mantener en sus puestos a los trabajadores neuquinos en el sector petrolero a pesar de

\footnotetext{
${ }^{7}$ (AGN), Ministerio del Interior, Provincias, Carpeta "La Comisión Nacional de Investigaciones", Asuntos Reservados. Año 1956, folio 1.
}

SCIO. Revista de Filosofía, n. ${ }^{\circ}$ 19, Noviembre de 2020, 127-153, ISSN: 1887-9853 
ser líderes políticos identificados con el peronismo, argumentando que esta "recomendación" se debía a una "realidad local" que, según ellos, era desconocida o no comprendida lo suficientemente por las autoridades del Gobierno federal, explicando la distancia sociogeográfica y cultural entre la Patagonia y Buenos Aires.

Este tema del "(des)conocimiento" o "falta de comprensión" de las "realidades locales" a nivel subnacional por parte de las autoridades de la dictadura ubicadas en Buenos Aires fue un tema de discusión y preocupación en estos años, especialmente por el estatus de la Patagonia como territorio nacional en proceso de provincialización, y no solo por la necesidad de aplicar políticas dirigidas contra el peronismo.

En el caso específico de Neuquén, la represión política local generó conflictos entre los propios antiperonistas que apoyaban a la dictadura, en especial por la forma en que se entendía la "realidad local" y por ende la forma en que se pretendían aplicar las políticas de "desperonización” en la zona.

Un ejemplo de este tipo de conflicto se puede ver en la forma en que el gobernador-interventor de la provincia de Neuquén, el capitán Ricardo Hermelo, presentó su disputa con el cura Ernesto Santo, el sacerdote católico de Plaza Huincul: el 7 de septiembre de 1956 el gobernador-interventor envió una solicitud al ministro del Interior del Gobierno federal, Laureano Landaburu, solicitando el traslado del cura de Plaza Huincul por haber demostrado "una intención perniciosa de crear un clima de malestar entre los trabajadores petroleros y sus respectivas autoridades. Por eso, señor Ministro, insisto en que se arregle de inmediato el traslado del citado sacerdote, porque una situación similar exige con urgencia que se adopte esta medida" 8 .

La solicitud del gobernador-interventor de la provincia de Neuquén se debió a una reunión que el cura había organizado con unos 300 trabajadores de YPF (empresa estatal de petróleo) el 25 de agosto de 1956 en el cine de la ciudad de Cutral Có, acto que las autoridades militares en Neuquén consideraron contrarias a la política del Gobierno Militar.

\footnotetext{
${ }^{8}$ Ministerio del Interior, Provincias, Carpeta "La Comisión Nacional de Investigaciones". Año 1956, folio 2, 508r.
} 
En su defensa, el sacerdote explicó al ministro que había convocado la reunión precisamente por la necesidad de reparar los errores cometidos por los funcionarios del Gobierno Militar en Neuquén, quienes habían despedido a veintitrés trabajadores sin causa previa.

En respuesta a una solicitud del gobernador-interventor de Neuquén, el sacerdote también envió una carta al secretario de Asuntos Religiosos del Gobierno Militar, Dr. Ricardo Lanusse, el 29 de septiembre de 1956, en la que explicaba lo sucedido, señalando que tuvo que interceder por la diferencia entre las políticas del Gobierno Militar a nivel nacional y su ejecución por parte de las autoridades en Neuquén, diferencia que había causado "el sufrimiento de veintitrés familias de Plaza Huincul". El sacerdote señalaba que su intención había sido tranquilizar a la población, ya que estas autoridades locales habían actuado contra las posiciones de la dictadura de la "Revolución Liberadora"".

Este conflicto y en especial la aclaración del sacerdote de que existían particularidades locales en Neuquén, que las autoridades impuestas por el Gobierno Militar no comprendieron y/o no consideraron en su trabajo (como el rol de la estatal YPF en la periferia de Neuquén), ilustra la importancia del contexto local durante la dictadura.

Las particularidades locales generaron conflictos que reformularon las prácticas políticas de la sociedad local durante la dictadura. Un ejemplo de estas prácticas puede observarse en el desarrollo de la famosa huelga de los trabajadores petroleros de Plaza Huincul, la cual comenzó oficialmente el 14 de febrero de 1958 tras la negativa de la empresa estatal YPF de aumentar los salarios de acuerdo con las demandas de los sindicatos petroleros locales (S.U.P.E.) (Lvovich, 2014).

El reclamo de los petroleros en Patagonia se basó en las diferencias en el costo de vida, en un contexto económico de alza en los precios. Ese mismo año, 1958, el costo de vida en Argentina se calculó en \$1142.70, una estimación basada en los precios en Buenos Aires. Sin embargo, los precios de la canasta familiar eran más altos en la Patagonia, por lo cual la prensa local en

\footnotetext{
${ }^{9}$ Ministerio del Interior, Provincias, Carpeta "La Comisión Nacional de Investigaciones". Año 1956, folio 5 .
} 
Neuquén cuestionaba cómo podía vivir una familia con un salario de \$1400, lo cual afirmaba que era imposible (Mases, Rafart, Lvovich, Quintar, 1998).

Frente a la decisión de los empleados petroleros de comenzar una huelga, el Gobierno Militar sancionó un decreto que estableció "la movilización parcial del personal argentino nativo, naturalizado o extranjero que preste servicios en la empresa estatal YPF". Este concepto de movilización significaba que los trabajadores tenían la obligación de ir a trabajar con el fin de garantizar los servicios.

Esta decisión del Gobierno Militar implicaba que los trabajadores de la empresa estatal de energía pasaban a estar bajo el Código de Justicia Militar, sin diferencias entre argentinos y extranjeros o peronistas y antiperonistas. Frente a esta decisión, la mayoría de los huelguistas en Plaza Huincul decidieron casi de inmediato continuar con la protesta e impedir la aplicación del decreto, todo ello independientemente de las discusiones políticas a nivel nacional (Castillo, 2005: 212).

Para continuar con la huelga en plena dictadura, los trabajadores petroleros de Plaza Huincul decidieron mudarse de sus hogares, escondiéndose en el pueblo o refugiándose en los campos y áreas aledañas. Esta decisión no solo colocó en un lugar secundario la división entre peronistas y anti-peronistas o inmigrantes o nacionales, sino que también motivó la participación colectiva de la población local ("huinculense") en una demanda común, la cual se veía legitimada principalmente por la residencia en un espacio común.

La decisión de los trabajadores de YPF visibilizaba de un modo explícito el desconocimiento (y/o falta de consideración) de la "realidad local" desde el Gobierno federal en Buenos Aires. Las políticas decididas frente a los huelguistas por las autoridades del Gobierno de la "Revolución Liberadora" ayudaron a convertir una demanda salarial, exigida por los trabajadores sindicalizados de una empresa estatal, en una demanda colectiva de la población local contra las "políticas del gobierno nacional ubicado en Buenos Aires".

Por ejemplo, Olga Lione, nacida fuera de Patagonia (en la Provincia de Córdoba) el 29 de marzo de 1928, se radicó en Cutral Có en 1957, donde trabajó como corresponsal del diario Río Negro. Olga recuerda que en el momento de la huelga junto a sus vecinos ayudaba a los huelguistas a esconderse de los militares cuando llegaban a buscarlos. Según el testimonio de Olga, las 
autoridades militares enviadas por el Gobierno no conocían a los habitantes del pueblo ni a los huelguistas a los que venían a detener. Esto facilitó que los habitantes locales ayudaran a los huelguistas. Una tarde, Olga recuerda, "estábamos sentados en la vereda con los vecinos, y por la noche venían los soldados a arrestar a los huelguistas. Estábamos juntos con los huelguistas hablando en la calle. Los soldados nos preguntaron si conocíamos a los huelguistas. ‘LLos conoces?' -todos sentados en la acera- '¿Los conoces?' 'No'. ¿Los conoces?' 'No, yo no'. Y estaban con nosotros en la vereda [...] más tarde lo sacábamos del pueblo" (Del Grosso, 2001: 89).

La decisión del Gobierno Militar, que buscaba asegurar la producción energética de la empresa estatal, terminó creando un marco de participación local basado en la percepción de injusticia que ponía en peligro, en el futuro cercano, las condiciones de vida en la sociedad local. En otras palabras, la respuesta del Gobierno Militar frente a la demanda salarial de los huelguistas cambió así el eje de la discusión política de estos pobladores.

La participación en la huelga de Plaza Huincul se vio reforzada por el papel de YPF en la sociedad patagónica (y específicamente dentro de la sociedad huinculense), papel que el Gobierno Militar de la "Revolución Libertadora" parecía ignorar (o no considerar) en sus políticas. Como recuerda Julio Durval Fuentes, quien nació en Cutral Có el 9 de julio de 1935 y trabajó para YPF Plaza Huincul de 1953 a 1986, "alrededor de YPF vivía mucha gente, mucha gente vivía bien: comerciantes, pintores, mecánicos, servicio doméstico [...] Toda esa gente descontenta también fortaleció la huelga. Los comerciantes lo notaron de inmediato. Dependían totalmente de los ingresos de la gente de YPF".

La actitud solidaria entre la población local no fue el resultado de una decisión político-partidaria o sindical. Entre los pobladores locales que apoyaron a los huelguistas (entre ellos indígenas, inmigrantes, así como trabajadores temporeros del exterior, especialmente de Chile y Bolivia) los comerciantes jugaron un papel importante, ayudando con diferentes alimentos. Entre los comerciantes que colaboraron con los huelguistas se pueden identificar tanto a personas como Elías Sapag (inmigrante de Oriente Medio y dueño de una carnicería y un supermercado durante la dictadura de la "Revolución Liberadora"), quien se había desempeñado como líder peronista en la zona, 
y comerciantes que se identificaban como antiperonistas, como Esteban Nolasco, dueño de una panadería y carnicería, y que junto a Amado Majluf (otro inmigrante de Medio Oriente) representaban a los partidos políticos opuestos al peronismo en Neuquén (Arias Bucciarelli, 2011).

La represión de la huelga por parte del Gobierno Militar cambió los datos y parámetros con los que los pobladores neuquinos calculaban y conjeturaban sobre su futuro, colocando el eje de las discusiones públicas por fuera de los temas políticos a nivel nacional, resaltando un riesgo local debido a la compleja relación con el Gobierno federal. Por ello, la conjetura sobre el peligro a corto y medio plazo, basado en las acciones del Gobierno Militar, se convirtieron en datos certeros que motivaron un cambio en la participación de la sociedad local.

Esta experiencia durante la huelga de los trabajadores petroleros de Plaza Huincul ilustra los cambios en las concepciones de futuro, y cómo estos afectan las decisiones y prácticas de los inmigrantes, en un contexto no solo inmigratorio. Porque si bien esta experiencia fue paralela a otras, demuestra cómo se introdujeron fundamentos y visibilizaron problemáticas gracias a las cuales se legitimaban ciertas conjeturas sobre escenarios futuros.

En síntesis, las experiencias de represión antiperonista en la Patagonia, especialmente en el contexto de provincialización, reforzaron percepciones sobre el futuro, las cuales motivaron una participación política de carácter localista, a pesar de la represión y la división política a nivel nacional (en todo el país). Esta identificación política local y este sentido de pertenencia a un colectivo local-regional se yuxtaponían a las identificaciones políticas en aquellos años en Argentina.

Por ello, las experiencias políticas en Neuquén durante la primera dictadura antiperonista en Argentina (1955-1958) terminaron cambiando ciertas concepciones del futuro, y configuran una preocupación por la situación local a corto plazo. Lo cual terminaría afectando no solo las identidades políticas sino también las prácticas y decisiones de los habitantes de Neuquén, incluidos los inmigrantes identificados como miembros de minorías étnicasreligiosas. 


\section{§5. CONCLUSIÓN}

Este artículo buscó introducir brevemente una discusión sobre el análisis de la concepción de futuro en los estudios históricos sobre la inmigración, a través de ejemplos en la región patagónica. Porque si bien las concepciones, conjeturas e imágenes del futuro juegan un rol en distintas decisiones, prácticas e identificaciones, los estudios que analizan la historia de los inmigrantes relacionan algunas cuestiones solo a sus experiencias previas, las cuales habrían sido características de sus zonas de origen.

Este artículo plantea que los estudios de los eventos, prácticas y experiencias de los inmigrantes en un tiempo pasado no solo pueden ser relacionados con experiencias previas o a zonas de origen. No solo porque el origen inmigratorio es también parte de un proceso de construcción, sino porque el pasado inmigratorio no necesariamente diseña las prácticas posteriores que estos desarrollan en sus nuevas sociedades de residencia y radicación.

Sin desconocer que la historia de los inmigrantes incluye un momento y una experiencia previa a su arribo a la nueva sociedad, esta historia también incluye una presunción, un cálculo y una creencia sobre el futuro. Más aún, la imagen de futuro participa en el proceso de decisión y desarrollo de nuevas prácticas, afectando también a la forma de considerar los eventos en aquel presente y en el pasado.

Considerando que las conjeturas, imágenes y concepciones sobre el futuro -o sobre posibles escenarios en el futuro- se basan en datos e informaciones que afectan a la vida de los individuos y sus sociedades en aquel presente, en este artículo se presentaron dos formas de indagar sobre la inmigración. En primer lugar, se buscó ejemplificar cómo decisiones en el proceso inmigratorio pueden ser examinadas a partir de las imágenes sobre el futuro, imágenes que fueron configuradas por aspectos materiales propios de la sociedad de residencia.

Las decisiones de los inmigrantes en la Patagonia -en especial de aquellos identificados como miembros de minorías étnico-religiosas- sobre cómo participar en el mercado laboral y en las discusiones sociales y políticas en sus primeros pasos en el país, demuestran la importancia que tuvieron las 
conjeturas sobre el futuro, las cuales se fundamentaron en el impacto que tuvieron las políticas gubernamentales en aquel contexto. Porque el comercio y la forma de comercializar de aquellos inmigrantes, y en especial sus decisiones como la venta en cuotas, pueden ser contextualizadas y relacionadas no tanto con su origen inmigratorio o con sus experiencias previas, sino con un modo de concebir las posibilidades futuras en aquella zona de residencia.

En segundo lugar, este artículo buscó ejemplificar cómo se generaron cambios materiales en un contexto particular, los cuales afectaron a decisiones y prácticas de la población local, incluida las de los inmigrantes. En particular, porque estos cambios implicaron nuevas y distintas informaciones a partir de las cuales los pobladores podían conjeturar sobre el futuro.

La decisión de los pobladores de Plaza Huincul de oponerse a la dictadura a partir de la respuesta del Gobierno Militar a la huelga de los empleados petroleros, cooperando entre ellos a pesar de las diferencias en sus identificaciones político-partidarias, significó un cambio en las prácticas políticas a partir de medidas que afectaban a la forma de conjeturar o fundamentar sobre el futuro. Las medidas del Gobierno Militar cambiaron aspectos materiales a partir de los cuales se podían suponer posibles futuros escenarios, y se configuró al respecto una sensación de peligro y riesgo en el futuro cercano entre la población local a raíz de estas decisiones del Gobierno federal.

El análisis histórico de la concepción de futuro para estudiar la historia inmigratoria requiere más investigación y discusiones teórico-metodológicas. Sin embargo, este artículo permite reflexionar sobre la forma de examinar la historia de los inmigrantes, especialmente de las minorías étnico-religiosas y sus formas de participar en distintos contextos históricos, ya que permite recapacitar sobre el rol desempeñado por las imágenes y suposiciones sobre el futuro.

En suma, este artículo plantea la necesidad de discutir cómo la concepción sobre el futuro también afectó el presente de los inmigrantes y la forma de relacionarse con su pasado. En especial, porque las imágenes de futuro formaron parte de la vida cotidiana de todos los habitantes del país, incluidos los inmigrantes. De esta manera, esta perspectiva de análisis permite afinar los estudios históricos de la participación de los inmigrantes en los procesos socioeconómicos y políticos, resaltando el papel de la incertidumbre en sus ex- 
periencias, prácticas e identificaciones, lo cual permite profundizar también nuestra comprensión de la historia inmigratoria y su relación con la historia política, social y económica de las zonas de radicación.

\section{REFERENCIAS BIBLIOGRÁFICAS}

Akmir, A. (1997). La Inmigración árabe en Argentina. En Raymundo Kabchi (coord.), El Mundo Árabe y América Latina. Madrid: Ediciones UNESCO. Akmir, A. (2011). Los árabes en Argentina. Rosario: UNR Editora.

Arias Bucciarelli, M. (2007). La Provincialización de Los Territorios Nacionales Durante El Primer Peronismo. Una Mirada Desde La Experiencia Neuquina. En Aixa Bona y Juan Vilaboa (coords.), Las Formas de La Política En La Patagonia. El Primer Peronismo En Los Territorios Nacionales. Buenos Aires: Biblos.

Arias Bucciarelli, M., González, A., Scuri, M. (2011). Radicales y Peronistas En La Conformación Del Sistema Político Neuquino. Revista de Historia (7), 153-168.

Bandieri, F., Favaro. O., Morinelli M. (1992). Historia de Neuquén. Buenos Aires: Editorial Plus Ultra.

Bandieri, Susana (2000). Neuquén: grupos de poder, estrategias de acumulación y prácticas políticas. Anuario IEHS 15, 179-205.

Carrizo, G. (2009). La Patagonia argentina en el período de entreguerras. Acerca de los orígenes de la Zona Militar de Comodoro Rivadavia. Antíteses, 2(4), 669-691.

Castillo, H. (2005). Neuquén. Crónica de una época... y la Fundación del M.P.N. Neuquén: Artes Gráficas Limay.

Danza, F. (2013). Liderazgo, elencos partidarios y selección de candidatos en el Movimiento Popular Neuquino entre 1961 y 1991. Revista de historia americana y argentina, 48(1, Tercera época).

Del Grosso, L. (2001). La huelga grande: Cutral-Có, la pueblada del 58. Neuquén: Asociación Trabajadores del Estado de Neuquén. 
Favaro, O. (2004). Sociedad y política: La interpelación y representación política de los ciudadanos neuquinos: Neuquén, Argentina (1958-1983). Prohistoria: historia, políticas de la historia 8, 151-164.

Favaro O. (ed.) (2005). Sujetos sociales y politica. Historia reciente de la norpatagonia argentina. Neuquén: Editorial La Colmena.

Gesser, S. S., Brauner, S. (2017). Aesthetics, politics and the complexities of Arab Jewish identities in authoritarian Argentina. En Contemporary Sephardic and Mizrahi Literature (pp. 53-78). Routledge.

Iuorno G. (2003). La historia política en Neuquén. Poder y familias libanesas. Avances del Cesor, 1-18.

Kloster, E. (1993). Dinámica espacial y tendencias en la redistribución de la población en la provincia del Neuquén. IV Encuentro de Geógrafos de América Latina, Mérida, Venezuela.

Lesser, J., Rein, R. (eds.) (2008). Rethinking Jewish-Latin Americans. New Mexico: University of New Mexico Press.

Lvovich, D. (2014). Orígenes de las dirigencias del peronismo en Neuquén. Estudios Sociales 46.1, 267-278.

Mases, E. (2003). Desperonización y Reperonización. La Norpatagonia como campo de batalla político-cultural 1955-1958. En El Peronismo Desde los Territorios a la Nación. Su historia en Rio Negro y Neuquén (1943-1958). Neuquén: Universidad Nacional del Comahue.

Mases H., Rafart E., Carlos G., Lvovich D, Quintar J. (1998). El mundo del trabajo en Neuquén 1930-1970. Neuquén: EDUCO.

Ministerio del Interior (1958). La Comisión Nacional de Investigaciones. Folios de los años 1956-1958.

Noyjovich, A., Rein, R. (2017). "For an Arab There Can Be Nothing Better Than Another Arab": Nation, Ethnicity and Citizenship in Peronist Argentina. The New Ethnic Studies in Latin America, 78-98.

Pérez Guilhou, Dardo, Seghesso, María Cristina (eds.). (2007). La Convención Constituyente de 1957. Partidos políticos, ideas y debates. Mendoza: Ex-libris / ASTREA. 
Rein, R. (2015). Los muchachos peronistas judios: los argentinos judios y el apoyo al justicialismo. Buenos Aires: Sudamericana.

Rosas, V. P., Gay, A. L. (2015). Push and pull factors of Latin American migration. En Demographic Analysis of Latin American Immigrants in Spain (pp. 1-27). Springer, Cham.

Ruffini, M., Blacha, L. (2013). La provincialización postergada de la Patagonia Argentina (1955-1958). Temas y Debates, (25), 59-81

Ruffini, M. (2016). Tiempos antiperonistas en la Patagonia argentina. La acción de las Comisiones Investigadoras durante la "Revolución Libertadora". Revista Paginas, 8 (16), 61-81.

Sapag L. (2008). Del Líbano a Neuquén: Genealogía de Una Pasión. Buenos Aires: Editorial Sudamericana.

Seligman, Martin E. P., et al. (2013). Navigating into the future or driven by the past. Perspectives on psychological science 8.2, 119-141.

Spinelli, M. E. (2005). Los vencedores vencidos: el antiperonismo y la "revolución libertadora". Editorial Biblos.

Taranda, D. (2012). Los orígenes del Movimiento Popular Neuquino en la provincia del Neuquén. En Francisco Camino Vela (comp.), El mundo de la política en la Patagonia norte (pp. 57-87). Neuquén: EDUCO.

Tcach, C. (2003). Golpes, proscripciones y partidos políticos. Nueva historia argentina 9, 1955-1976.

Velcamp, Theresa A. (1997). The Historiography of Arab Immigration to Argentina: The Intersection of the Imaginary and the Real Country. Immigrants \& Minorities 16(1-2), 227-248. 